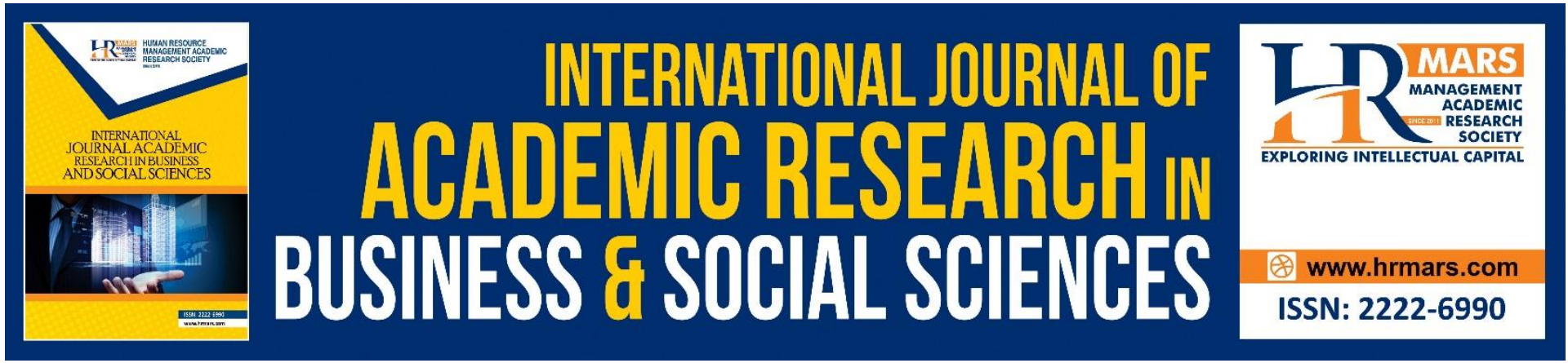

\title{
The Impact of Job Insecurity on Psychological Wellbeing (Case Study on the Workers on Private Company in Damascus)
}

\section{Yara Abu Alniaj}

To Link this Article: http://dx.doi.org/10.6007/IJARBSS/v10-i12/8111

DOI:10.6007/IJARBSS/v10-i12/8111

Received: 11 November 2020, Revised: 23 November 2020, Accepted: 16 December 2020

Published Online: 24 December 2020

In-Text Citation: (Alniaj, 2020)

To Cite this Article: Alniaj, Y. A. (2020). The Impact of Job Insecurity on Psychological Wellbeing (Case Study on the Workers on Private Company in Damascus). International Journal of Academic Research in Business and Social Sciences, 10(12), 981-999.

Copyright: (c) 2020 The Author(s)

Published by Human Resource Management Academic Research Society (www.hrmars.com) This article is published under the Creative Commons Attribution (CC BY 4.0) license. Anyone may reproduce, distribute, translate and create derivative works of this article (for both commercial and non-commercial purposes), subject to full attribution to the original publication and authors. The full terms of this license may be seen at: http://creativecommons.org/licences/by/4.0/legalcode

Vol. 10, No. 12, 2020, Pg. 981 - 999

Full Terms \& Conditions of access and use can be found at http://hrmars.com/index.php/pages/detail/publication-ethics 


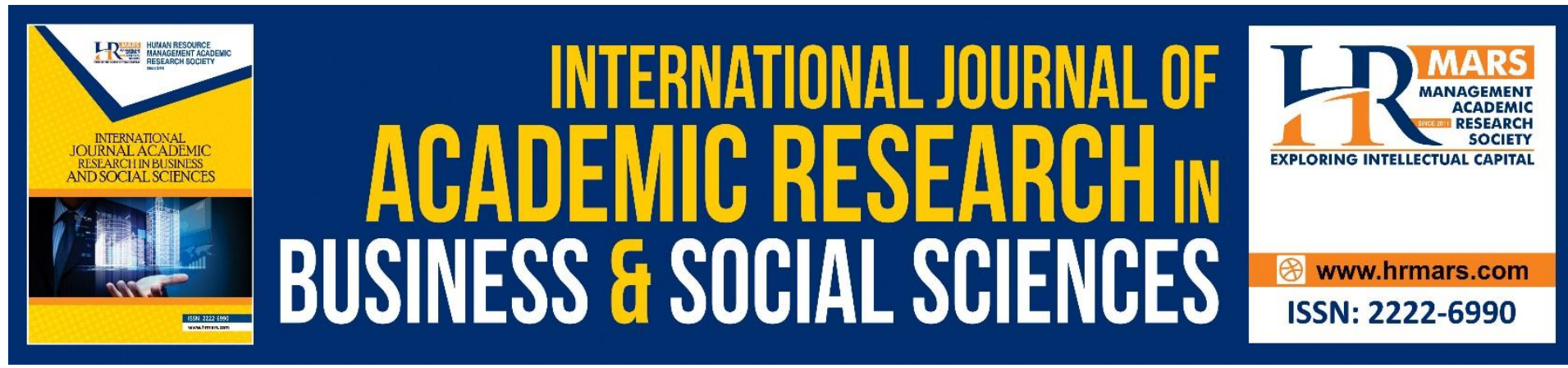

\title{
The Impact of Job Insecurity on Psychological Wellbeing (Case Study on the Workers on Private Company in Damascus)
}

\author{
Yara Abu Alniaj \\ Researcher, Department of Human Resources Management, Higher Institute of Business \\ Administration, Damascus, Syria \\ Email: yaraaboalnj@yahoo.com
}

\begin{abstract}
The purpose of this study is to clarify the concept of job insecurity and psychological well being. The study also aims to identify the effect of job insecurity on psychological well being in private sector companies in Damascus. In order to achieve the objectives of the study, a questionnaire developed for data collection. The researcher used (SPSS) to analyze the data. The study produced a series of results, the most prominent of which are:

No significant effect of job insecurity on the dimensions of psychological well being (autonomy, environmental mastery, personal growth, positive relations with others, purpose of life, self- acceptance) for workers in the private sector companies in the city of Damascus, and there are significant effects of job insecurity on overall psychological well being for workers in the private sector companies in the city of Damascus. Moreover, the relationship between the dimensions of psychological well being (autonomy, positive relations with others, purpose of life, Self-Acceptance) and the lack of job security is a weak force, and the relationship between the dimensions of psychological well being (Environmental Mastery, personal growth) and the lack of job security is a medium force. Moreover, the relationship between the psychological well being and job insecurity is medium strength.
\end{abstract}

Keywords: Psychological Well Being, Job Insecurity

\section{Introduction}

As a result of entering the private sector alongside public sector in Syria and attracting a large proportion of employment because of working conditions it provides in terms of high salaries, great experience and training courses, and as a result of the conditions plaguing the country, the closure of many industrial and commercial establishments and the high unemployment rate, workers are facing arbitrary layoffs and expulsion for the simplest The reasons are due to the firm's ability to obtain suitable alternatives at any point. Thus, we find that a sense of job security, which is one of the basic requirements of workers, is not available, and this affects their psychological state and makes them vulnerable to problems such as depression, boredom, tension, anxiety and insecurity from the possibility of losing the source of income, which is essential and important under the current circumstances. 


\section{Problem and Questions of the Study}

The Syrian worker suffers from a state of job insecurity, despite the high salaries paid by the private sector, there are many workers subjected to dismissal or threats of it at the slightest mistake, and thus this affects their psychological well being. Here, the research problem appears to us, which is to measure the effect of job insecurity on the psychological well being of the worker. Thus, the main question can formulated in the research: What is the effect of job insecurity on the psychological well being of workers in the private sector in Damascus? Therefore, this research attempts to answer the following questions:

- Is there a relationship between job insecurity and psychological well being for workers in private sector companies?

- What is the level of job insecurity for workers in private sector companies?

- What is the level of psychological well being for workers in private sector companies?

- Does the level of job insecurity and psychological well being differ according to the demographic characteristics of individuals working in private sector companies?

- Do demographic variables (gender, age, educational level, occupational level) play a modified role on the relationship between job insecurity and psychological well being?

\section{Importance of the Study}

The current research clarifies both the concepts of job insecurity and psychological well being for workers in the private sector in Damascus. It will also contribute to knowing the degree of job insecurity and the degree of psychological well being for workers in light of the Syrian crisis.

\section{Research Objectives}

* Clarify the concepts of job insecurity and psychological well being.

* Identify the reality of the level of job insecurity and the level of psychological well being for workers in the private sector in Damascus.

* Reaching results through which some recommendations can be formulated that help decision-makers in companies to avoid causes that may lead to negative effects, whether on the side of the company or the worker.

\section{Hypotheses of the Study}

H1: There is a significant impact of job insecurity on the dimensions of psychological well being for workers in private sector companies in Damascus.

H2: There are statistically significant differences in the level of job insecurity for workers according to (gender, age, educational level, job level) in the private sector companies in Damascus.

H3: There are statistically significant differences in the level of psychological well being of workers according to (gender, age, educational level, job level) in the private sector companies in Damascus.

H4: Demographic variables (gender, age, educational level, job level) play a modified role between job insecurity and psychological comfort for workers in private sector companies in Damascus. 


\section{Lack of Job Security Introduction}

We notice in modern times increased volatility of economic and financial crisis and the outbreak of war and the problems faced by many countries of the world which affected the economic situation, closed many companies and lost a large number of workers and signed many of the workers in the danger zone and the threat of losing their job in any Moment.

In addition to increasing competition between companies, which seek to introduce continuous updates and developments, such as the introduction of modern technology and the replacement of the machine in the place of humans.Therefore, there has been an increase in concern about job insecurity, its causes and effects on the individual and the organization (in terms of increased work turnover, low loyalty, affiliation, satisfaction, trust, etc.) (Richter, 2011).

\section{Defining Job Insecurity}

Greenhalgh \& Rosenblatt (1984) defined job insecurity as the inability to continue to maintain a desired job in a job threaten situation.

Borg \& Elizur (1992) defined it as the possibility of losing a job or the fear of losing a job. Sverke, Hellgren \& Naswall (2002) defining it is a subjective and involuntary expectation of an event that may cause loss of work. De Witte (2005) defined it as the risk of job cuts and job loss.

\section{Reasons for the Lack of Job Security among Workers}

Changes in the labor market and the emergence of globalization have dramatically changed consumer habits, prompting companies to devise strategies to meet the new and increasing demands of consumers in an uncertain environment. Cascio (1998) found that the organization's profit is through following one of two options: either reducing costs or reducing the number of workers within the organization.

Thus, we find that changes in the organization are among the main sources of job insecurity and among these changes (Ashford, 1989)

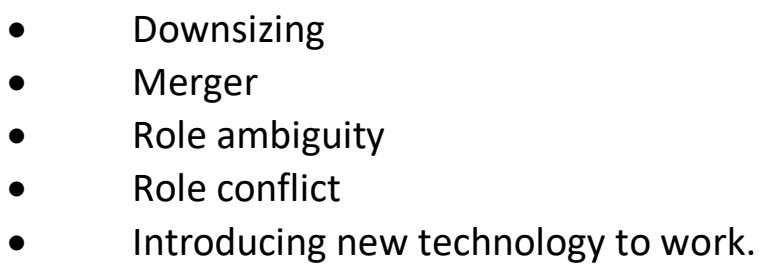

\section{Results of the Lack of Job Security}

Greenhalf ( 1984) explain that job insecurity negatively affects productivity, job stability and ability to adapt to others, as well as causes anxiety and lack of sleep. Sverke (2002) also found that job insecurity has many effects at the level of the individual, the organization, and the environment outside work, whether in the short or long term, and it expressed as follows:

At the individual level: In the short term, we find that job insecurity negatively affects work trends in terms of integration and job satisfaction. In the long term, we find that it affects physical and mental health. 
At the level of the organization: In the short term, we find that job insecurity negatively affects the organization's trends in terms of trust and loyalty to the organization. In the long term, we find its negative impact on work-related behaviors (intention to leave work) and not affect performance.

And (De Witte, 2005) indicated that it is considered one of the causes of work stress and has a clear effect on employees' health, general well being and psychological well being.

In a study by the University of Michigan of America, explained that the pressures and strains that workers are exposed to in the event of job insecurity have negative effects on health in the short term in terms of emotions, causing insecurity (dissatisfaction, disturbance, tension) and from the behavioral point of view. It leads to (absenteeism from work, loss of concentration, smoking and possibly alcohol or drug abuse) and physiologically causing (high blood pressure). (Burgard et la, 2008)

In the long term, job insecurity causes psychological frustration, reduces immunity, causes mental and physical ailments, and leads to job burnout (Schreursa et la, 2010).

\section{Psychological well being \\ Definition of Psychological Well Being}

Definitions of psychological well being varied, the most important of which is according to the researcher Bradburn (1969) defining psychological well being through a model expressed in the following form: "The individual is in a good psychological state when he has an excess of positivity and a lack of negativity, and the individual is in a bad psychological state when He has an excess of negativity and a lack of positivity".

In Ryff (1989) defined psychological well being as "the absence of negative feelings in the individual or the existence of happiness alone" and set six basic dimensions for it: Autonomy, environmental mastery, personal growth, positive relationships with others, the purpose of life, self-acceptance.

The researcher Ryff (1995) re-defined psychological well being as "not achieving pleasure but rather the pursuit of perfection that represents a person's realization of his true purpose and has six dimensions."

\section{Dimensions of Psychological Well Being}

According to Ryff \& Singer (1996), to achieve psychological well being, it is not sufficient for a person to achieve a high score in one dimension only, but also to achieve a balance in all dimensions in order to enjoy high psychological well being. These six dimensions are:

Autonomy: This dimension measures the ability to resist social pressures by thinking and acting in certain ways and evaluating oneself according to several criteria. It also expresses the extent to which individuals adopt their own ideas and behaviors and the extent of their dependence on the ideas of others.

The Environmental Mastery Dimension: This dimension measures a person's ability to manage the surrounding environment, coordinate outdoor activities, and take advantage of surrounding opportunities.

Personal Growth: This dimension measures the individual feeling of continuous development, the extent of his vision of the development and growth of his skills and abilities, 
the extent of improvement in behavior over time. Also expresses the extent of openness to new experiences.

Positive Interpersonal Relation: It measures warmth, satisfaction and confidence in relationships with others. It measures the extent of individual sympathy with others and the ability to give people and provide assistance.

Purpose in life: It measures an individual's ability to direct his goals in life and the extent of his beliefs that give meaning to life in addition to feeling the meaning of past and present events in life.

Self-Acceptance: This dimension measures the individual's feelings about the self and the extent of his recognition and acceptance of the various aspects of the self, including the good and the bad. This dimension also measures the individual's feelings about past events.

\section{Methodology of Research}

The research method used is the descriptive and analytical approach, and it defined as "a method or method for studying social phenomena in an organized scientific manner from the time to reach a briefing of the phenomenon and describe it in terms of its size, causes, or forms .... etc."

In addition to following the inductive approach, which is defined as "the inductive approach that begins with the particles to derive laws and generalities from them, as it starts from the samples to generalize the results, and depends on verification by observing the subject of experimentation and controlling the various variables."

\section{Study Population and Sample}

The research population consists of workers in the private sector for the year 2014. The individuals of the research sample we chosen by a simple random sampling method. Data collected by distributing questionnaires to workers.

\section{Study Sample}

A simple random sample of (290) employees of the private sector. The questionnaire distributed to the entire sample with 236 retrieved questionnaires. Ten questionnaires excluded because they were not valid for statistical analysis. 


\begin{tabular}{|l|l|c|c|}
\hline Variables & Variables categories & Quantity & Percentage \\
\hline \multirow{4}{*}{ Sex } & Male & 112 & $49.6 \%$ \\
\cline { 2 - 4 } & Female & 114 & $50.4 \%$ \\
\hline \multirow{5}{*}{ Educational Level } & From 22 till 27 & 78 & $34.5 \%$ \\
\cline { 2 - 4 } & From 28 till 33 & 54 & $23.9 \%$ \\
\cline { 2 - 4 } & From 34 till 39 & 44 & $19.5 \%$ \\
\cline { 2 - 4 } & More than 40 & 50 & $22.1 \%$ \\
\hline \multirow{5}{*}{ Job Level } & School & 14 & $6.2 \%$ \\
\cline { 2 - 4 } & Middle Institute & 44 & $19.5 \%$ \\
\cline { 2 - 4 } & Bachelor & 142 & $62.8 \%$ \\
\cline { 2 - 4 } & Master Degree & 26 & $11.5 \%$ \\
\hline & $\begin{array}{l}\text { Executive } \\
\text { management }\end{array}$ & 130 & $57.5 \%$ \\
\cline { 2 - 4 } & $\begin{array}{l}\text { Executive } \\
\text { management }\end{array}$ & 86 & $38.1 \%$ \\
\cline { 2 - 4 } & Senior management & 10 & $4.4 \%$ \\
\hline
\end{tabular}

Table (1). The characteristics of the study sample

\section{Test the Validity and Reliability of the Search Tool}

The validity of the paragraphs of the questionnaire verified in two ways:

Apparent honesty: The research tool presented to a group of specialized arbitrators at the Higher Institute of Business Administration (HIBA) in the field of research, so that the scale became in its final form and approved to apply to the pilot sample.

The reliability of the search tool test: The alpha Cronbach used to find out the validity and reliability of the measurement tool for all axes. The following table shows that the reliability coefficients for all research measures axes are high and statistically acceptable reliability coefficients because they are greater than 0.60 and indicate the stability of the paragraphs of each axis.

\begin{tabular}{|l|c|c|}
\hline & $\begin{array}{c}\text { Number of } \\
\text { paragraphs }\end{array}$ & $\begin{array}{c}\text { Alpha Cronbach } \\
\text { coefficient }\end{array}$ \\
\hline Job insecurity axis & 6 & 0.92 \\
\hline Psychological well being & 3 & 0.86 \\
\hline The first dimension: Autonomy & 3 & 0.75 \\
\hline The second dimension: environmental mastery & 3 & 0.81 \\
\hline The third dimension: personal growth & 3 & 0.71 \\
\hline $\begin{array}{l}\text { The fourth Dimension: positive relationships } \\
\text { with others }\end{array}$ & 3 & 0.71 \\
\hline The fifth dimension: the purpose of life & 3 & 0.75 \\
\hline The sixth dimension: self-acceptance & $\mathbf{1 8}$ & $\mathbf{0 . 9 5}$ \\
\hline Total psychological well being axis & & \\
\hline
\end{tabular}

Table (2). Alpha Cronbach test 


\section{Results}

The first hypothesis: There is a significant effect of job insecurity on the psychological well being dimensions of workers in private sector companies in Damascus.

Verification of the first sub-hypothesis: There is a significant effect of job insecurity on the Autonomy dimension of psychological well being for workers in private sector companies in Damascus.

\begin{tabular}{|l|l|l|l|l|}
\hline $\begin{array}{l}\text { The result is at the } \\
\text { level of } \\
(0.05) \text { significance }\end{array}$ & $\begin{array}{l}\text { Indication level } \\
\text { (Sig) }\end{array}$ & $\begin{array}{l}\text { Regression } \\
\text { coefficient } \\
\text { (Beta) }\end{array}$ & $\begin{array}{l}\text { Adjusted R } \\
\text { Square }\end{array}$ & $\begin{array}{l}\text { Correlation } \\
\text { coefficient } \\
\text { (R) }\end{array}$ \\
\hline $\begin{array}{l}\text { The effect is } \\
\text { significant }\end{array}$ & 0.0000 & -0.464 & 0.179 & 0.432 \\
\hline
\end{tabular}

Table (3). Testing first sub-hypothesis

It can be seen from the previous table that the value of the correlation coefficient between the two dependent variables (after Autonomy for psychological well being) and independent (job insecurity) amounted to: $R=0.432$, and this indicates that the relationship between the dependent and independent variables is a weak relationship. As for the value of the coefficient of determination $R$ Square $=0.179$, we have seen that $82.1 \%$ of the changes in the dependent variable are not due to the change in the independent variable, and only $17.9 \%$ of the changes in the dependent variable are due only to the independent variable. Since the value of the regression coefficient (Beta) is negative, this indicates the existence of a negative relationship between job insecurity and after Autonomy for psychological well being.

The level of significance of the linear regression coefficient was (0.000), which is smaller than the level of significance used in the hypothesis test of 0.05 , and this invites us to reject the null hypothesis and accept the alternative hypothesis and thus: "There is a significant effect of job insecurity at the distance of Autonomy for the psychological well being of workers in private sector companies In the city of Damascus" .

The equation for linear correlation for this model is $Y=B 0+B 1 X 1$ i.e. $Y=4.546-0.464 X 1$

Where $X$ is the independent variable (functional insecurity) and $Y$ is the dependent variable (after Autonomy for psychological well being). That is, the level of Autonomy increases by (0.464) degrees whenever the level of job insecurity decreases by one degree.

Verification of the second sub-hypothesis: There is a significant impact of job insecurity on the dimension of control over the environment for the psychological well being of workers in private sector companies in Damascus

\begin{tabular}{|l|l|l|l|l|}
\hline $\begin{array}{l}\text { The result is at the } \\
\text { level of } \\
\text { (0.05) significance }\end{array}$ & $\begin{array}{l}\text { Indication } \\
\text { level } \\
\text { (Sig) }\end{array}$ & $\begin{array}{l}\text { Regression } \\
\text { coefficient } \\
\text { (Beta) }\end{array}$ & $\begin{array}{l}\text { Adjusted R } \\
\text { Square }\end{array}$ & $\begin{array}{l}\text { Correlation } \\
\text { coefficient } \\
\text { (R) }\end{array}$ \\
\hline $\begin{array}{l}\text { The effect is } \\
\text { significant }\end{array}$ & 0.000 & -0.581 & 0.283 & 0.538 \\
\hline
\end{tabular}

Table (4). Testing second sub-hypothesis

It can be seen from the previous table that the value of the correlation coefficient between the two dependent variables (after controlling the environment for psychological well being) and 
independent (job insecurity) amounted to: $R=0.538$, and this indicates that the relationship between the dependent and independent variables is a medium strength relationship. As for the value of $\mathrm{R}$ Square $=0.29$, we have found that $71.7 \%$ of the changes in the dependent variable are not due to the change in the independent variable and only $28.3 \%$ of the changes in the dependent variable are due only to the independent variable. Since the value of the regression coefficient (Beta) is negative, this indicates the existence of a negative relationship between job insecurity and after controlling the environment for psychological well being.

The level of significance of the linear regression coefficient was (0.000), which is smaller than the level of significance used in the hypothesis test of 0.05 , and this invites us to reject the null hypothesis and accept the alternative hypothesis and thus: "There is a significant effect of job insecurity at the control distance of the environment for the psychological well being of workers in companies The private sector in Damascus.

The equation for linear correlation for this model is $Y=B 0+B 1 X 1$ i.e. $Y=4.46-0.518 X 1$

Where $X$ is the independent variable (functional insecurity) and $Y$ is the dependent variable (after Autonomy for psychological well being). That is, the level of control over the environment increases by $(0.518)$ degrees whenever the level of job insecurity decreases by one degree.

Verification of the third sub-hypothesis: There is a significant effect of job insecurity on the personal growth dimension of psychological well being for workers in private sector companies in Damascus.

\begin{tabular}{|l|l|l|l|l|}
\hline $\begin{array}{l}\text { The result is at the } \\
\text { level of } \\
(0.05) \text { significance }\end{array}$ & $\begin{array}{l}\text { Indication } \\
\text { level } \\
\text { (Sig) }\end{array}$ & $\begin{array}{l}\text { Regression } \\
\text { coefficient } \\
\text { (Beta) }\end{array}$ & $\begin{array}{l}\text { Adjusted R } \\
\text { Square }\end{array}$ & $\begin{array}{l}\text { Correlation } \\
\text { coefficient } \\
\text { (R) }\end{array}$ \\
\hline $\begin{array}{l}\text { The effect is } \\
\text { significant }\end{array}$ & 0.000 & -0.581 & 0.267 & 0.523 \\
\hline
\end{tabular}

Table (5). Testing third sub-hypothesis

It can be seen from the previous table that the value of the correlation coefficient between the two dependent variables (after personal growth of psychological well being) and independent (job insecurity) amounted to: $R=0.523$, and this indicates that the relationship between the dependent and independent variables is a medium strength relationship. As for the value of $R$ Square $=0.267$, we see that $3.37 \%$ of the changes in the dependent variable are not due to the change in the independent variable, and only $26.7 \%$ of the changes in the dependent variable are due only to the independent variable. Since the value of the regression coefficient (Beta) is negative, this indicates that there is a negative relationship between job insecurity and after the personal growth of psychological well being.

The level of significance of the linear regression coefficient was (0.000), which is smaller than the level of significance used in the hypothesis test of 0.05 , and this invites us to reject the null hypothesis and accept the alternative hypothesis and thus: "There is a significant effect of job insecurity on the dimension of personal growth of psychological well being for workers in the sector companies Private in Damascus'

The equation for linear correlation for this model is $Y=B 0+B 1 X 1$ i.e. $Y=4.946-0.581 X 1$ Where $X$ is the independent variable (job insecurity) and $Y$ is the dependent variable (after personal development of psychological well being). That is, the level of personal growth increases by ( 0.581 ) degree whenever the level of job insecurity decreases by one degree.

Verification of the fourth sub-hypothesis: There is a significant effect of job 
insecurity on the dimension of positive relations with others for psychological well being for workers in private sector companies in Damascus.

\begin{tabular}{|l|l|l|l|l|}
\hline $\begin{array}{l}\text { The result is at the } \\
\text { level of } \\
(0.05) \text { significance }\end{array}$ & $\begin{array}{l}\text { Indication level } \\
\text { (Sig) }\end{array}$ & $\begin{array}{l}\text { Regression } \\
\text { coefficient } \\
\text { (Beta) }\end{array}$ & $\begin{array}{l}\text { Adjusted R } \\
\text { Square }\end{array}$ & $\begin{array}{l}\text { Correlation } \\
\text { coefficient } \\
\text { (R) }\end{array}$ \\
\hline $\begin{array}{l}\text { The effect is } \\
\text { significant }\end{array}$ & 0.000 & -0.332 & 0.144 & 0.389 \\
\hline
\end{tabular}

Table (6). Testing fourth sub-hypothes

It can be seen from the previous table that the value of the correlation coefficient between the two dependent variables (after positive relationships with others for psychological well being) and independent (job insecurity) amounted to: $R=0.389$. This indicates that the relationship between the dependent and independent variables is a weak relationship. As for the value of R Square $=0.144$, we see that $85.6 \%$ of the changes in the dependent variable are not due to the change in the independent variable, and only $14.4 \%$ of the changes in the dependent variable are due only to the independent variable. Since the value of the regression coefficient (Beta) is negative, this indicates that there is a negative relationship between job insecurity and after positive relationships with others.

The level of significance of the linear regression coefficient (0.000) was smaller than the level of significance used in the hypothesis test of 0.05 . This invites us to reject the null hypothesis and accept the alternative hypothesis: "There is a significant effect of job insecurity on the dimension of positive relationships with others for the psychological well being of workers in Private sector companies in Damascus

The equation for linear correlation for this model is $Y=B 0+B 1 X 1$ i.e. $Y=3.655-0.332 X 1$

Where $X$ is the independent variable (job insecurity) and $Y$ is the dependent variable (after personal development of psychological well being). That is, the level of positive relationships with others increases by (0.332) degrees whenever the level of job insecurity decreases by one degree.

Verification of the fifth sub-hypothesis: There is a significant effect of job insecurity on the purpose of life for psychological well being for workers in private sector companies in Damascus.

\begin{tabular}{|l|l|l|l|l|}
\hline $\begin{array}{l}\text { The result is at the } \\
\text { level of } \\
(0.05) \text { significance }\end{array}$ & $\begin{array}{l}\text { Indication } \\
\text { level } \\
\text { (Sig) }\end{array}$ & $\begin{array}{l}\text { Regression } \\
\text { coefficient } \\
\text { (Beta) }\end{array}$ & $\begin{array}{l}\text { Adjusted R } \\
\text { Square }\end{array}$ & $\begin{array}{l}\text { Correlation } \\
\text { coefficient } \\
\text { (R) }\end{array}$ \\
\hline $\begin{array}{l}\text { The effect is } \\
\text { significant }\end{array}$ & 0.000 & -0.463 & 0.242 & 0.499 \\
\hline
\end{tabular}

Table (7). Testing fifth sub-hypothesis

We can see from the previous table that the value of the correlation coefficient between the two dependent variables (after the purpose of life for psychological well being) and independent (job insecurity) amounted to: $R=0.499$, and this indicates that the relationship between the dependent and independent variables is a weak relationship. As for the value of 
R Square $=0.242$, it turns out that $75.8 \%$ of the changes in the dependent variable are not due to the change in the independent variable and only $24.9 \%$ of the changes in the dependent variable are due only to the independent variable. Since the value of the regression coefficient (Beta) is negative, this indicates the existence of a negative relationship between job insecurity and the purpose of life.

The level of significance of the linear regression coefficient (0.000) was smaller than the level of significance used in the hypothesis test of 0.05 . This invites us to reject the null hypothesis and accept the alternative hypothesis and thus: "There is a significant effect of job insecurity on the dimension of life for the psychological well being of workers in companies the private sector in Damascus

The equation for linear correlation for this model is $Y=B 0+B 1 X 1$ i.e. $Y=4.129-0.463 X 1$ Where $X$ is the independent variable (job insecurity) and $Y$ is the dependent variable (after life's purpose of psychological well being). That is, the level of the purpose of life increases by (0.350) degrees whenever the level of job insecurity decreases by one degree.

Verification of the sixth sub-hypothesis: There is a significant effect of job insecurity on the self-acceptance of the psychological well being of workers in private sector companies in Damascus.

\begin{tabular}{|l|l|l|l|l|}
\hline $\begin{array}{l}\text { The result is at the } \\
\text { level of } \\
(0.05) \text { significance }\end{array}$ & $\begin{array}{l}\text { Indication level } \\
\text { (Sig) }\end{array}$ & $\begin{array}{l}\text { Regression } \\
\text { coefficient } \\
\text { (Beta) }\end{array}$ & $\begin{array}{l}\text { Adjusted R } \\
\text { Square }\end{array}$ & $\begin{array}{l}\text { Correlation } \\
\text { coefficient } \\
\text { (R) }\end{array}$ \\
\hline $\begin{array}{l}\text { The effect is } \\
\text { significant }\end{array}$ & 0.000 & -0.446 & 0.192 & 0.446 \\
\hline
\end{tabular}

Table (8). Testing sixth sub-hypothesis

It appears from the previous table that the value of the correlation coefficient between the two dependent variables (after self-acceptance of psychological well being) and independent (job insecurity) amounted to: $R=0.446$, and this indicates that the relationship between the dependent and independent variables is a weak relationship. As for the value of the coefficient of determination R Square $=0.192$, we have seen that $80.8 \%$ of the changes in the dependent variable are not due to the change in the independent variable, and only $19.2 \%$ of the changes in the dependent variable are due only to the independent variable. Since the value of the regression coefficient (Beta) is negative, this indicates the existence of a negative relationship between job insecurity and self-acceptance of psychological well being.

The level of significance of the linear regression coefficient was $(0.000)$ which is smaller than the level of significance used in the hypothesis test of 0.05 . This invites us to reject the null hypothesis and accept the alternative hypothesis and thus: "There is a significant effect of job insecurity on the distance of self-acceptance of the psychological well being of workers in sector companies Private in Damascus'

The equation for linear correlation for this model is $Y=B 0+B 1 X 1$ i.e. $Y=3.894-0.446 X 1$

Where $X$ is the independent variable (job insecurity) and $Y$ is the dependent variable (after self-acceptance of psychological well being). That is, the level of self-acceptance increases by (0.446) degrees whenever the level of job insecurity decreases by one degree.

Verification of the main hypothesis: There is a significant effect of job insecurity on the psychological well being of workers in private sector companies in Damascus. 


\begin{tabular}{|l|l|l|l|l|}
\hline $\begin{array}{l}\text { The result is at the } \\
\text { level of } \\
(0.05) \text { significance }\end{array}$ & $\begin{array}{l}\text { Indication } \\
\text { level } \\
\text { (Sig) }\end{array}$ & $\begin{array}{l}\text { Regression } \\
\text { coefficient } \\
\text { (Beta) }\end{array}$ & $\begin{array}{l}\text { Adjusted R } \\
\text { Square }\end{array}$ & $\begin{array}{l}\text { Correlation } \\
\text { coefficient } \\
\text { (R) }\end{array}$ \\
\hline $\begin{array}{l}\text { The effect is } \\
\text { significant }\end{array}$ & 0.000 & -0.472 & 0.289 & 0.544 \\
\hline
\end{tabular}

Table (9). Testing main hypothesis

It can be seen from the previous table that the value of the correlation coefficient between the two variables dependent (psychological well being) and independent (job insecurity) amounted to: $R=0.544$. This indicates that the relationship between the dependent and independent variables is a medium strength relationship. As for the value of the coefficient of determination $\mathrm{R}$ Square $=0.289$, we have seen that $71.1 \%$ of the changes in the dependent variable are not due to the change in the independent variable and only $28.9 \%$ of the changes in the dependent variable are due only to the independent variable. Since the value of the regression coefficient (Beta) is negative, this indicates a negative relationship between job insecurity and psychological well being.

The level of significance of the linear regression coefficient was (0.000), which is smaller than the level of significance used in the hypothesis test of 0.05 . This invites us to reject the null hypothesis and accept the alternative hypothesis and thus: There is a significant effect of job insecurity on the psychological well being of workers in private sector companies in the city Damascus" .

The equation for linear correlation for this model is $Y=B 0+B 1 X 1$ i.e. $Y=4.301-0.472 X 1$ Where $X$ is the independent variable (job insecurity) and $Y$ is the dependent variable (psychological well being). That is, the level of psychological well being increases by $(0.472)$ degrees whenever the level of job insecurity decreases by one degree.

The second hypothesis :There are statistically significant differences in the level of job insecurity for workers according to (gender, age, educational level, and occupational level (in the private sector companies in Damascus.

5.2.1 Verification of the first sub-hypothesis :There are statistically significant differences in the level of job insecurity for workers by gender in private sector companies in Damascus.

\begin{tabular}{|c|c|}
\hline The result is at the level of significance (0.05) & Indication level (Sig) \\
\hline There is no moral difference & 0.115 \\
\hline
\end{tabular}

Table (10). Independent Sample T test

From the previous table we note that Sig is equal to 0.115 greater than the significance level of 0.05 and therefore we accept the null hypothesis and reject any alternative hypothesis that "no statistically significant differences in the level of job insecurity for employees by sex and private companies in the city of Damascus".

5.2.2. Verification of the second sub-hypothesis :There are statistically significant differences in the level of job insecurity for workers according to age in private sector companies in Damascus. 


\begin{tabular}{|c|c|}
\hline The result is at the level of significance (0.05) & Indication level \\
\hline There is no moral difference & 0.128 \\
\hline
\end{tabular}

Table (11). One-Way ANOVA test

Showing of the variance analysis of the differences in the level of lack of job security for workers by age for workers in the private sector companies that the level of moral (0.128) which is greater than the level of auctioneer of 0.05 , which invites us to accept the null hypothesis and rejected the alternative hypothesis " :No no statistically significant differences On the level of job insecurity for workers by age in private sector companies in Damascus.

Verification of the third sub-hypothesis :There are statistically significant differences in the level of job insecurity for workers according to educational level in private sector companies in Damascus.

\begin{tabular}{|c|c|}
\hline $\begin{array}{c}\text { The result is at the level of significance } \\
(0.05)\end{array}$ & Indication level (Sig) \\
\hline There is no moral difference & 0.302 \\
\hline
\end{tabular}

Table (12). One-Way ANOVA test

Showing of the variance analysis of the differences in the level of job insecurity as a variable of educational level of workers in the private sector companies that the level of moral (0.302) which is greater than the level of auctioneer of 0.05 , which invites us to accept the hypothesis of nowhere and rejected the alternative hypothesis ":No no significant differences Statistics on the level of job insecurity for workers according to educational level in private sector companies in Damascus.

Verification of the fourth sub-hypothesis:There are statistically significant differences in the level of job insecurity for workers according to the job level in private sector companies in Damascus.

\begin{tabular}{|c|c|}
\hline The result is at the level of significance (0.05) & Indication level \\
\hline There is no moral difference & 0.807 \\
\hline
\end{tabular}

Table (13). One-Way ANOVA test

Showing of the variance analysis of the differences in the level of job insecurity as a variable career level of employees in the private as sector companies reached a significant level $(0.807)$ which is a large level of auctioneer of 0.05 , which invites us to accept the null hypothesis and rejected the alternative hypothesis, namely " :No no differences Statistical significance in the level of job insecurity for workers according to the job level in private sector companies in Damascus. 
Hypothesis is the third gingival :There are statistically significant differences in the level of psychological well being for workers by (sex, age, educational level, career level (in the private sector companies in the city of Damascus.

Verification of the first sub-hypothesis:There are statistically significant differences in the level of psychological well being of workers by gender in private sector companies in Damascus.

\begin{tabular}{|c|c|}
\hline $\begin{array}{c}\text { The result is at the level of significance } \\
(0.05)\end{array}$ & Indication level (Sig) \\
\hline There is no moral difference & 0.237 \\
\hline
\end{tabular}

Table (14). Independent Sample T test

Note that Sig is equal to 0.237 greater than the significance level of 0.05 and therefore we accept the null hypothesis and reject any alternative hypothesis that "no statistically significant differences in the level of psychological well being of employees by sex in the private sector companies in the city of Damascus".

Verification of the second sub-hypothesis:There are statistically significant differences in the level of psychological well being of workers according to age in private sector companies in Damascus.

\begin{tabular}{|c|c|}
\hline The result is at the level of significance (0.05) & \multicolumn{1}{|c|}{ Indication level } \\
\hline There is a moral difference & 0.047 \\
\hline
\end{tabular}

Table (15) One-Way ANOVA test

Showing of the variance analysis of the differences in the level of psychological well being of employees by age for workers in the private sector companies that the abstract level (0.047) which is smaller than the level auctioneer of 0.05 , which leads us to reject the hypothesis of nowhere and accept the alternative hypothesis: ie ", There are statistically significant differences in the level of Psychological well being for workers according to age in private sector companies in Damascus.

Verification of the third sub-hypothesis:There are statistically significant differences in the level of psychological well being of workers according to educational level in private sector companies in Damascus.

\begin{tabular}{|c|c|}
\hline $\begin{array}{c}\text { The result is at the level of significance } \\
(0.05)\end{array}$ & Indication level (Sig) \\
\hline There is no moral difference & 0.287 \\
\hline
\end{tabular}

Table (16). One-Way ANOVA Test

Showing of the variance analysis of the differences in the level of lack of job security for workers according to the educational level of workers in the private sector companies that the moral level (0.287) which is a large level of auctioneer of 0.05 , which leads us accept the null hypothesis and reject the alternative of any hypothesis " :No there are differences $A$ 
statistical indication of the level of psychological well being for workers according to educational level in private sector companies in Damascus.

5.3.1. Verification of the fourth sub-hypothesis :There are statistically significant differences in the level of psychological well being of workers according to their occupational level in private sector companies in Damascus.

\begin{tabular}{|c|c|}
\hline The result is at the level of significance (0.05) & Indication level (Sig) \\
\hline There is no moral difference & 0.873 \\
\hline
\end{tabular}

Table (17). One-Way ANOVA test

Showing of the variance analysis of the differences in the level of lack of job security for employees by career level for workers in the private sector companies that the moral level ( 0.873 (which is a large level of auctioneer of 0.05 , which invites us to accept the null hypothesis and rejected the alternative hypothesis, namely ":No there are differences $A$ statistical indication of the level of psychological well being for workers according to their occupational level in private sector companies in Damascus.

The fourth hypothesis: demographic variables (gender, age, educational level, job level) play a modified role between job insecurity and psychological well being for workers in private sector companies in Damascus.

5.3.2. The first sub-hypothesis :demographic variables (gender) play a modified role between job insecurity and psychological well being for workers in private sector companies in Damascus.

\begin{tabular}{|l|l|l|}
\hline & Adjusted R Square & Beta \\
\hline Males & 0.196 & -0.459 \\
\hline Females & 0.376 & -0.602 \\
\hline
\end{tabular}

Table (18). Gender

We notice from the previous table that $19.6 \%$ of the psychological state of male workers affected by job insecurity, and $37.6 \%$ of the psychological state of female workers affected by job insecurity.

Consequently, we find that women's psychological well being is affected by job insecurity more than men. The reason for this is that organizations in times of crises abandon women more than men.

The second sub-hypothesis :demographic variables (age) play a modified role between job insecurity and psychological well being for workers in private sector companies in Damascus.

\begin{tabular}{|l|l|l|}
\hline & Adjusted R Square & Beta \\
\hline From 22 to 27 & 0.296 & -0.503 \\
\hline 28 to 33 & 0.163 & -0.520 \\
\hline 34 to 39 & 0.157 & -0.389 \\
\hline 40 or more & 0.349 & -0.422 \\
\hline
\end{tabular}

Table (19). Age 
We notice from the previous table that $29.6 \%$ of the psychological state of workers between the ages of 22 and 27 affected by job insecurity, and $16.3 \%$ of the psychological state of workers between the ages of 28 and 33 affected by job insecurity .We also find that $15.7 \%$ of the psychological state of workers between the ages of 34 and 39 affected by job insecurity, and $34.9 \%$ of the psychological state of workers aged 40 or over is affected by job insecurity. Consequently, we find that the psychological well being of workers who reach work 40 or more affected by job insecurity more than in other age groups. We also find that psychological well being among workers between the ages of 34 and 39 is less affected by job insecurity. This is due to fact that workers of this age have high years of experience and therefore their wages are high, and organizations in the event of crises abandon the workers with high wages.

The third sub-hypothesis :demographic variables (educational level) play a modified role between job insecurity and psychological well being for workers in private sector companies in Damascus.

\begin{tabular}{|l|l|l|}
\hline & Adjusted R Square & Beta \\
\hline High School & 0.734 & -1.030 \\
\hline Average Institute & 0.526 & -0.821 \\
\hline University & 0.19 & -0.355 \\
\hline Postgraduate & $\mathbf{0 . 3 9 3}$ & $-\mathbf{0 , 5 0 0}$ \\
\hline
\end{tabular}

Table (20). Educational level

We notice from the previous table that $73.4 \%$ of the psychological state of workers who have obtained a high school diploma affected by job insecurity. We also find that $52.6 \%$ of the psychological state of workers with an intermediate institute degree affected by job insecurity.We also find that $19 \%$ of the psychological state of workers with university education affected by job insecurity. We also note that $39.3 \%$ of the psychological state of highly-educated workers is affected by job insecurity.

Consequently, we find that the psychological well being of workers who have obtained a secondary school certificate affected by job insecurity more than the rest. We also find that psychological well being among workers who have a university education less affected by job insecurity . The reason for this is that workers with a high school diploma easily abandoned by the organization, and they have few job opportunities compared to the large numbers of university graduates.

The fourth sub-hypothesis :demographic variables ( job level) play a modified role between job insecurity and psychological well being for workers in private sector companies in Damascus.

\begin{tabular}{|l|l|l|}
\hline & Adjusted R Square & Beta \\
\hline Executive management & 0.335 & -0.571 \\
\hline Intermediate or supervisory management & 0.293 & -0.433 \\
\hline Senior management & 0.246 & -0.321 \\
\hline
\end{tabular}

Table (21). Job level 
From the previous table, $33.5 \%$ of the psychological state of employees in the executive administration affected by job insecurity, and $31.1 \%$ of the psychological state of middle management workers affected by job insecurity . We also find that $0.3 \%$ of the psychological state of workers in senior management affected by job insecurity.

Consequently, we find that the psychological well being of employees in executive management affected by job insecurity more than workers in middle management and workers in higher management.

\section{Results and Discussions}

- $\quad$ There is a significant impact of job insecurity on the dimensions of psychological well being (Autonomy, environmental mastery, personal growth, positive relationships with others, the purpose of life, self-acceptance) for workers in private sector companies in Damascus.

- $\quad$ There is a significant effect of job insecurity on the overall psychological well being of workers in private sector companies in Damascus.

- The relationship between the dimensions of psychological well being (Autonomy, positive relationships with others, the purpose of life, self-acceptance) and job insecurity is a weak relationship.

- $\quad$ The relationship between the dimensions of psychological well being (environmental control, personal growth) and job insecurity is a medium strength relationship.

- The relationship between overall psychological well being and job insecurity is medium strength.

- $\quad$ There are no statistically significant differences in the level of job insecurity for workers according to (gender, age, educational level, job level) in private sector companies in Damascus.

- $\quad$ There are no statistically significant differences in the level of psychological well being of workers according to (gender, educational level, career level) in private sector companies in Damascus. However, there are statistically significant differences in the level of psychological well being of workers according to age in private sector companies.

- $\quad$ The psychological well being of women affected by greater job insecurity than men.

- $\quad$ The psychological well being of workers who reach work 40 or more affected in the case of job insecurity more than other age groups. We also find that psychological well being among workers between the ages of 34 and 39 less affected by job insecurity.

- $\quad$ The psychological well being of workers with a high school diploma affected by job insecurity more than the rest. We also find that psychological well being among workers who have a university education are less affected by job insecurity.

- $\quad$ The psychological well being of employees in the executive management affected in the case of job insecurity more than workers in middle management and workers in higher management.

\section{Recommendations}

After displaying the search results, we recommend the following:

- $\quad$ The institution must inform employees in a transparent and objective manner about the dimensions of the crisis it is going through and encourage the participation of workers in proposing solutions necessary to limit its negative effects, so that the workers feel that they are part of the organization and are not surprised by the decisions that may be taken. 
- Improving the surrounding environment for workers by giving more delegations within the scope of work, which contributes to improving the psychological well being of workers.

- $\quad$ Assigning workers to additional tasks and duties that contribute to increasing their skills and competencies, raise their sense of the importance of the work they perform, help them grow and develop, and contribute to improving their psychological well being.

- $\quad$ Organizations must work to consolidate a sense of reassurance, especially among women, by raising the morale and emphasizing the principle of equal opportunities.

- $\quad$ Organizations should be keen to raise the feeling of safety for workers over the age of 40 by taking administrative measures such as (redistributing workers to different departments and branches or re-assigning them to new tasks and positions) through which it aims to maintain them.

- Increasing the sense of job security for people with low educational qualifications by emphasizing their important role in the organization.

- $\quad$ The necessity for the elements of middle management to interact with the elements of the executive management and with their problems and to work on developing the relationship of the executive management with the middle management.

\section{Theoretical \& Practical Implications}

This study has several theoretical implications, First This research is considered from the researchers' point of view, and after reviewing the sources of the research, one of the first studies that touched The Impact of Job Insecurity on Psychological Well being, and applying this research in Syrian Private companies, the current study is an enrichment of the scientific and research aspect of the Syrian Private companies, due to the role of these institutions in developing the private sector in Syria, which is currently considered one of the most important sectors supporting the Syrian economy. Second, we have revealed the influence of High job insecurity on psychological well being. Moreover, our results provide evidence for notion that the success of an organization depend on the ability of how to improve surrounding environment, in light of the great competition between organizations.

Our findings also have several practical implications. First Assist human resource managers in increasing the psychological well being. Second, they showed that employees' perceptions of High job insecurity are of pivotal importance regarding their psychological well being.

Based on the current finding, Private companies should pay attention to work environment, raising the morale and emphasizing the principle of equal opportunities, increasing skills and raising the feeling of safety among employees.

\section{References}

Ashford, S., Lee, C., \& Bobko, P. (1989). Content, causes, and consequences of job insecurity: A theory-based measure and substantive test. Academy of Management Journal

Bradburn, N. (1969). The Structure of Psychological Well-Being. Aldine Publishing Company: Chicago

Cascio. (1998). Learning from outcomes: Financial experiences of 311 firms that have downsized, In M. K. Gowing, J. C. Kraft \& J. C. Quick (Eds.), The new organizational reality: Downsizing, restructuring, and revitalization. Washington: American Psychological Association

Cuyper, N., Oettel, C., Berntson, E., De Witte, H., \& Alarco, B. (2008). Employability and Employees' Well-Being:Mediation by Job Insecurity. Journal Compilation 
De Witte, H. (2005). Job Insecurity: Review of The International Literature on Definition, Prevalence, Antecedents and Consequences. Journal of Industrial Psychology

De Witte, H. (1999). Job insecurity and psychological well-being: review of the literature and exploration of some unresolved issues. European Journal of Work and Organizational Psychology

ELIZUR, B. (1992). Job insecurity: correlates, moderators and measurement. International Journal of Manpower

Richter, A. (2011). Job Insecurity and its Consequences: Investigating Moderators, Mediators and Gender, Stockholm University

Rosenblatt, G. (1984). Job insecurity: Toward conceptual clarity Academy of Management Review. Human Resources Management

Ryff, C. (1995). Psychological well-being in adult life. Current Directions in Psychological Science

Ryff, C. (1996). Burton Singer, Psychological Well- Being: Meaning, Measurement, and Implications for Psychotherapy Research. Psychother Psychosom

Schreursa, B., Emmerikb, H., Notelaersc, G., \& De Witte, H. (2010). Job insecurity and employee health: The buffering potential of job control and job self-efficacy. Work \& Stress, Vol. 24, No. 1

Sverke, M., Hellgren, J., \& Näswall, K .(2002). No security: A meta-analysis and review of job insecurity and its consequences. Journal of Occupational Health Psychology 